\title{
Status of the TransiEnt Library: Transient simulation of coupled energy networks with high share of renewable energy
}

\author{
Lisa Andresen ${ }^{1}$ Pascal Dubucq ${ }^{2}$ Ricardo Peniche Garcia ${ }^{3}$ \\ Günter Ackermann $^{2}$ Alfons Kather ${ }^{3}$ Gerhard Schmitz ${ }^{1}$ \\ Hamburg University of Technology, Am Schwarzenberg-Campus 1, Hamburg, Germany \\ ${ }^{1}$ Institute of Thermo-Fluid Dynamics, \{andresen, schmitz $\}$ @tuhh. de \\ ${ }^{2}$ Institute for Electric Power Systems and Automation, \{dubucq, ackermann \} @tuhh. de \\ ${ }^{3}$ Institute of Energy Systems, \{peniche, kather $\}$ atuhh. de
}

\begin{abstract}
The Modelica library Transient is being developed within the research project TransiEnt.EE. After completion, the library will be freely available and will provide a framework to model coupled energy supply grids, i.e. electricity, district heating, and gas grids, including their corresponding producers, consumers and storage systems. This paper presents the current status of the library and outlines the library's structure and the modeling concept. The application possibilities of the library are presented in an exemplary simulation where the city of Hamburg is selected as the reference system. The impact of a high share of fluctuating renewable energy generation in the electric grid and the integration of excess electricity in the district heating network is presented.

Keywords: coupled energy grids, electricity, district heating, gas, dynamic simulation, renewable energy
\end{abstract}

\section{Introduction}

In 2011, the European Union set ambitious emission reduction targets to contribute to the abatement of climate change. These targets pursue a 80 to $95 \%$ reduction of greenhouse gas emissions by 2050 compared to the 1990 emission levels (European Commission, 2011). To reach this goal, Germany aims to cover $80 \%$ of its gross electric energy consumption with renewable energies (RE) by the year 2050 (BMWi, 2014). However, the timely offset between RE generation and electricity demand, together with limited inter-regional electricity transport capacities leads already to regional imbalances, which results in RE curtailment.

The so-called energy triangle that illustrates the main goals of energy policy considers not only environmental protection, but also economic efficiency and security of supply. With Germany's Energiewende the objective of less greenhouse gas emissions is heavily promoted. This must not lead to an unaffordable and unreliable energy supply system. Thus, all three objectives should be taken into account when comparing different future scenarios. Consequently, simulations are necessary.

The research project TransiEnt.EE (Hamburg University of Technology, 2013-2016) currently being executed at the Hamburg University of Technology has two main objectives: a) to analyze and compare different strategies for the integration of renewable energies in urban energy systems considering transient effects derived from coupling of energy grids and $b$ ) to develop a freely available Modelica library which allows this kind of studies. The project started in May 2013 and will be finished in October 2016.

After completion, the library TransiEnt (Transient Energy Networks) will be made available under the terms of the Modelica license agreement. The current development is performed using Dymola (Dassault Systemes, 2012). Modelica was chosen as the developing language because it allows multi-domain simulation, which is handy when simulating coupled electricity, district heating and gas grids. Besides, its object-oriented features simplify the development process and usability of the library.

This paper is structured as follows: first, the technical background of coupled energy grids is presented. Afterwards, the library's package structure and modeling approach are presented, together with a brief description of other used Modelica libraries and the definition of the main interfaces. Finally, an example simulation is presented which shows the applicability of the library.

\section{Technical Background}

The TransiEnt library covers the whole energy infrastructure with its corresponding producers, consumers, grids and storage systems. A brief description of these and the properties and basic differences of the electricity, heating and gas networks will be given. 


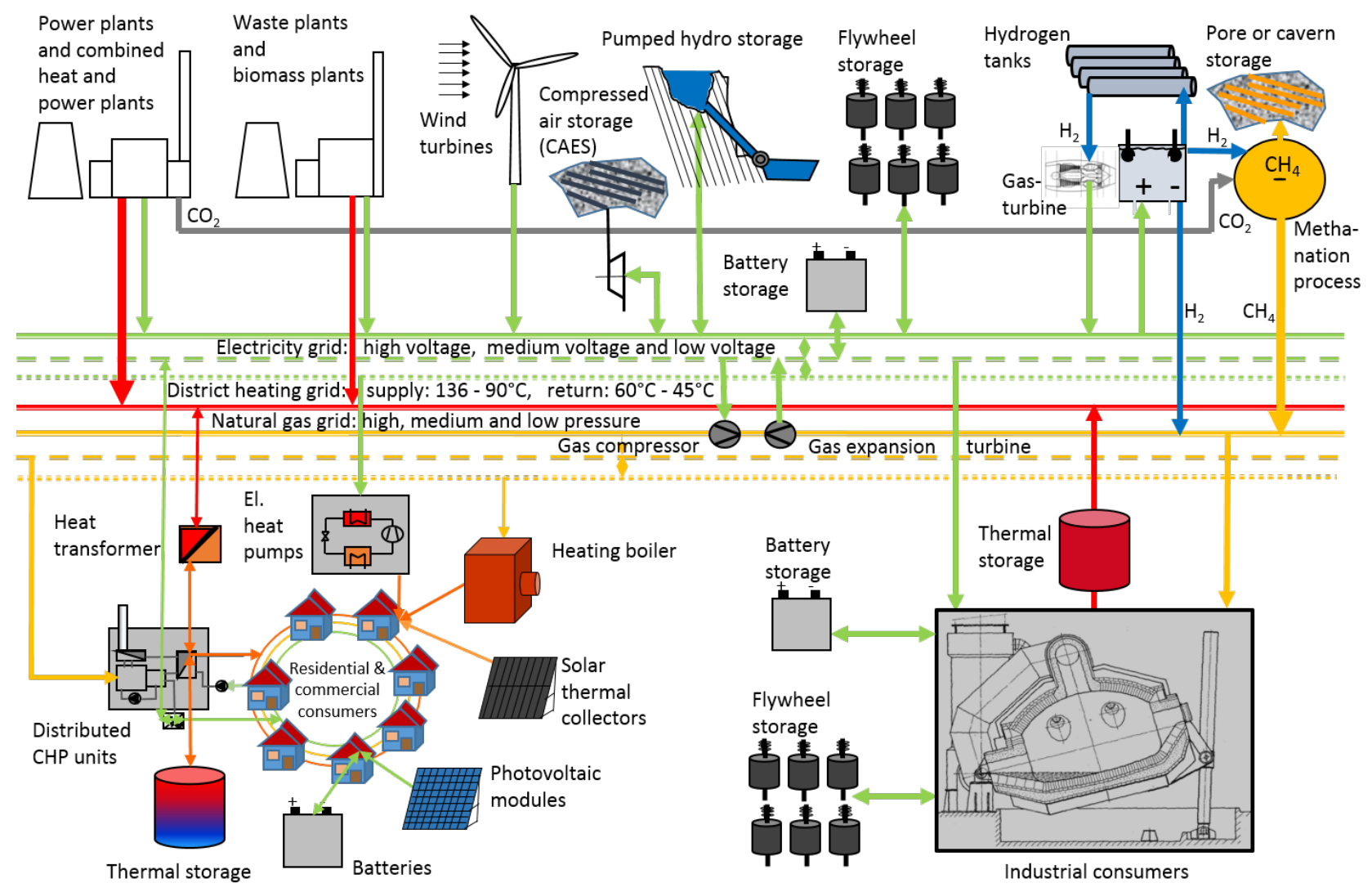

Figure 1. Scheme of coupled electricity, district heating and gas energy supply systems including their corresponding smalland large-scale producers, consumers, and storage systems.

\subsection{The Energy Supply Infrastructure}

The energy supply infrastructure can basically be grouped into four parts: the producers, the distributing grids, the consumers, and the storage systems, which are briefly defined in the following:

- Producers are small- to large-scale technical units that convert energy into electric power, and / or thermal power.

- Grids serve for transporting and distributing energy from the sources or producers to the consumers.

- Consumers devalue the final energy by "using" it. They are characterized by electric and thermal power loads.

- Storage systems are technical units that accumulate a form of mechanical or inner energy. They can be localized at any point of the energy supply infrastructure and serve for timely decoupling of production and utilization.

Figure 1 shows schematically the electric, heat and gas supply infrastructure with its participants. In the top third of the scheme, large scale fossil and renewable power plants, as well as central storage units are shown. In the middle, the three distributing grids are displayed. Furthermore, different consumers, smaller storage units, and decentralized energy converters are shown in the bottom of the scheme.

As coupled energy grids are the purpose of modeling, the links between the grids shall be described briefly in the following. Some of them are well-known and defined by the conversion of gas to electric or thermal power or both. For consistency reasons these shall be called gasto-power, gas-to-heat, and gas-to-power-and-heat technologies, respectively. Recently, other connection technologies are in development and tested in pilot plants. These are often called power-to-heat and power-to-gas technologies. The name indicates the direction of energy conversion. Power-to-gas units use electric power to split up water into hydrogen and oxygen. The hydrogen can be further deployed in the methanation process to obtain methane. Both products can be used directly or fed into the natural gas grids. Power-to-heat units convert electric into thermal power, either directly by using resistance heaters or electrode boilers or thermodynamically more efficient by the use of heat pumps. The thermal energy can then be used directly or fed into the district heating grid. Both, power-to-gas and power-to-heat systems, could be used in the future to adapt and increase the amount of electrical renewable generation used. 


\subsection{Differences and Dynamics of the Grids}

There are some differences between the electricity, heating, and gas infrastructures. To begin with, natural gas is a primary energy carrier and needs to be converted to be usable, whereas in the heating and electricity grids the transported energy has already gone through at least one lossy conversion. Another difference is that in heating and gas grids energy can be stored to some extend. In the electricity grid, on the other hand, almost no capacity is available for storage. Thus, demand and supply have to be equal at any time, which makes the stability of the electricity grid a challenging task. This is why there exists an European integrated network coordinated by the ENTSO-E (ENTSO-E, 2015) to balance skew positions supra-regionally, in an efficient and fast way. Consequently, the electricity networks of cities or even countries are not isolated, which has to be considered in the modeling. This is different for district heating and gas grids. Heating grids only supply smaller regions at most as big as cities. The thermal power is produced by local (combined) heat (and power) plants corresponding to the local demand. Germany's gas economy highly relies on imports, which normally do not coincide with the demand but are done according to the price, storing gas during summer and releasing it in winter. Delivery bottlenecks are rather seldom and are not accounted for in the modeling. Gas markets are regional and the chemical composition of the gas mixture differs regionally and could be more and more influenced by local biogas and hydrogen feed-in in the future. Therefore, heating and gas grids need to be modeled with mass transfer and local sources and sinks to some extent.

As the name of the library suggests, transient simulations of the coupled energy networks are carried out. This is to account for ramp rates, reaction times, and dead times of the coupled system's components. The need for dynamic simulations shall be explained by two examples. For instance, the off-take of gas from the grid is not constant during the year or even the day. Consequently, the maximum volume flow rate of hydrogen only a defined Vol.- $\% \mathrm{H}_{2}$ is allowed - fed into the natural gas grid varies. Thus, there could be moments with excess renewable power where the gas grid is not able to take up more hydrogen. Another example concerns the inertia of the heating grid. The propagation velocity of a change in temperature in the district heating grid is approximately $8.7 \mathrm{~km} / \mathrm{h}$ for a heating water mass flow of $3300 \mathrm{t} / \mathrm{h}$ (Chudzienski, 1987). This means, that a sudden rise in thermal power consumption takes around 2.3 hours to be noticeable by means of a lower return temperature at the production plant in $20 \mathrm{~km}$ distance. In the electricity network, on the contrary, changes in demand are noticeable instantaneously. The model has to account for these different time constants.

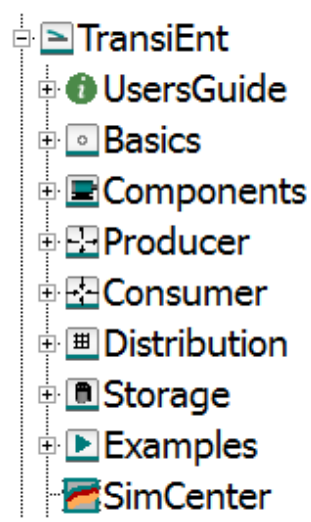

Figure 2. Top level tree of the Transient library package.

\section{The TransiEnt Library}

The broad range of physics and fields considered in the TransiEnt library demands some effort in readable modeling and an user-friendly structure. Moreover, the level of detail (LoD) of the models has to be suitable for the task of simulation: complex single and coupled energy supply systems with various producers, consumers, storage systems, and distribution networks as well as their links for areas as big as cities.

In the following, the content of the library package is described, the modeling principles is explained, and a brief introduction to other used Modelica libraries as well as details to the main interfaces are given.

\subsection{Library Structure}

Figure 2 shows the top level tree of the TransiEnt library. The layout of the library was chosen carefully in the purpose of reuse-ability by applicants as well as expand-ability by model developers. The Basics package contains supporting classes like functions, units, blocks, media records, data tables, icons, and interfaces. Single components, e.g. electrical machines, pumps, and pipes, are structured within the components package. These first two packages are meant to be used and modified by advanced users and developers only, whereas the remaining packages are meant for users that want to build up energy systems in order to examine different scenarios. These packages are named after the four participating groups in the energy supply system: producer, consumer, distribution, and storage. Within the Producer package there are small and large, conventional and renewable plants converting primary energy into electric work, heat or both. The Consumer package comprises models of electric power and thermal power loads for households, commercial buildings, industry as well as for bigger areas like city districts or whole cities. Distribution is composed of electric, heat, and gas distribution elements. Within the storage package there are different power-to-power (e.g. pumped 
hydro storage), heat-to-heat (e.g. sensible water storage tanks), gas-to-gas (e.g. caverns), as well as powerto-heat and power-to-gas converters. The last package Examples contains examples for the different system models in general and for the examined system of the city of Hamburg. These examples allow the users to easily understand the usage of components and the scope of application of the library.

\subsection{Global Parameters and Statistics}

A basic concept that was partly taken from the ClaRa library (ClaRa Library, 2015) and was extended to the requirements of the TransiEnt library is the concept of the global Simcenter model. This model has basically three purposes within the TransiEnt package:

- setting global parameters for the three energy supply infrastructures, e.g. the media in the gas and heat grids or the nominal frequency in the electric grid,

- choosing ambient condition time lines, which can be changed and extended easily by extending a modified MSL CombiTimeTable and setting the path to the data file in ASCII or MAT-file format, and

- collecting simulation statistics, i.e. the produced and consumed power and energy, the costs for heat and electricity, and the $\mathrm{CO}_{2}$ emissions, each statistic variable calculated in every time step.

Each sub-component within the Transient package has an outer instance of the model simcenter called simcenter. The executable model then has to have an inner simcenter. Here, the settings for the simulated system and all its objects are defined and the statistics are collected.

To avoid the need of post-processing steps for the analysis of scenarios the SimCenter model provides the user with summarized results of the simulated energy system. For this purpose, it contains four gathering blocks: electric power, heating power, incurred costs and emissions. Each block gathers information from distributed sensors located within the component models and allocates them to specific types, e.g. total produced energy by RE.

\subsection{Modeling Principles}

In general, the principles of the modeling within the TransiEnt package can be summarized as follows:

- flat hierarchy for high readability,

- high flexibility by means of exchangeable models with different physical effects considered, and
- easily changeable boundary conditions.

The modeling principles mainly arose due to the complexity of a coupled energy supply system, containing systems with very different time constants (s. section 2) and also control units. Simulating a big coupled system is a challenge, which is why the systems can be built up of simple models (with low level of detail) in the first instance. If the analysis of the results shows that some effects should be more detailed, this can be done by replacing the simple model by a more advanced one. The choice of the physical effects and also dynamics to be considered highly depend on the question to be answered. On the other side, the level of detail (LoD) is restricted by the number of equations and computing power, respectively. For instance, the model resolution can be higher if only a city district shall be simulated and not a whole city. One of the questions to be answered within the scope of the TransiEnt.EE project is a about the level of detail of the subsystems. Since the accuracy of the whole system depends on the accuracy of the subsystems, the LoD of the latter have to be in such a way that all physical and transient effects that have a considerable impact on the overall results $\left(\mathrm{CO}_{2}\right.$ emissions $)$ are modeled. On the other hand, the simulation of the whole system should still be computationally manageable within reasonable CPU times.

\subsection{Level of Detail}

As mentioned before, the purpose of the TransiEnt library is not the optimization of a single component of the system, e.g. the efficiency of a battery stack, but rather the optimization of the interaction of various components in order to improve the integration of renewable energies. Therefore, there exists a certain limitation in the level of detail of the subsystems that won't be exceeded.

Besides distinguishing between static and dynamic models, the modeling approaches can generally be classified into table-based models, models that are based on characteristic lines and / or transfer functions, spatially averaged, and spatially discretized balance equationbased models. Table-based models are based on the CombitimeTable and require data input. Some electric and thermal power data for consumers and electric power data for renewable energy plants are provided in quarter hourly resolution for Hamburg.

For the main participating groups (s. section 2.1) the following approaches are implemented:

- Producer: table-based models, transfer functionbased models, balance equation-based models,

- Grids: electrical grid only considers power flow and center of inertia grid frequency; heating and gas grids are built up of pipes that can be spatially discretized and use real fluid mixtures to consider evaporation in the heating network and hydrogen feed-in in the high pressure gas grid, 


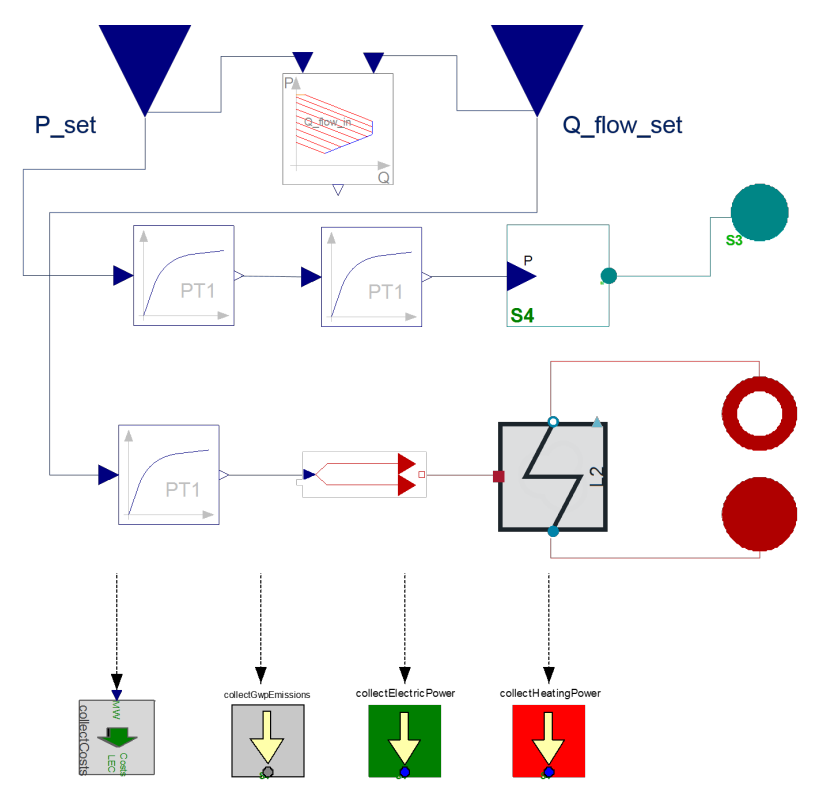

Figure 3. Example of a subsystem composed of models with different levels of detail.

- Consumer: table-based models, balance equationbased models,

- Storage: transfer function-based models, balance equation-based models.

The model complexity of coupled urban energy systems leads to a need of simplifying the subsystem models. A trade-off between simplicity and high LoD is required. In the TransiEnt library, this is achieved by combining table-based, transfer function-based and balance equation-based models. To illustrate this concept, a very simple combined heat and power (CHP) plant model is shown in Figure 3. The incoming set values for the electricity and heat production are received from external schedulers via real input connectors and then transferred to a table-based model and to first order blocks. The table-base model in this example is a lookup table with plant-specific heat input rates. These values can then be used to calculate load-dependent efficiency values. On the other hand, the first order blocks can be parameterized to represent plant-specific power gradients. A balance equation-based heat exchanger model from the ClaRa library is used in this example to calculate the heat transfer to the district heating water. Finally, the four collecting sensors at the bottom of the figure calculate generation costs, emissions and generation values and transfer these results to the inner simcenter instance.

More detailed combined models and models based solely on balance equations are currently under development. The later models can be used for detailed analysis of smaller time-frames. However, their complexity makes their usage for annual simulations of coupled energy systems impractical.

\subsection{Usage of Other Libraries}

Besides the Modelica Standard Library (MSL), TransiEnt mainly uses two other libraries, that will be introduced briefly.

The free Modelica library ClaRa (ClaRa Library, 2015; Brunnemann et al., 2012) was released in March 2015 and is the main product of the research project DynCap (Kather et al., 2014). ClaRa (Clausius Rankine) models the transient thermal behavior of power plants and power systems. The library contains all components of the water-steam cycle and the gas treatment path of power plants. Basic components like pipes and heat exchangers are used in the TransiEnt library in the heating systems. Power plant models with a low level of detail can be used as well. ClaRa does not use media models from the MSL but from the TILMedia Suite.

TILMedia (TLK Thermo GmbH, 2015) is an interface library to provide thermophysical properties from various existing fluid and solid property databases as well as own implementations to different applications, e.g. Modelica/Dymola or Matlab/Simulink. Media models used in ClaRa are provided and can be used freely. Further necessary models for the Transient library (e.g. natural gas) will also be freely available. For other implementations beyond the scope of the TransiEnt.EE research project a supplementary license will be necessary.

TILMedia was chosen due to better numerical performance and robustness compared to Modelica.Media which was tested during the DynCap project (Brunnemann et al., 2012; Kather et al., 2014). These factors are regarded as critical for simulation of big coupled and closed loop systems considered here. Furthermore, Modelica. Media so far does not provide media properties for real gas and fluid mixtures.

\subsection{Interfaces}

There are two different types of interfaces: one for fluids and one for electric terminals. The fluid interface is taken from ClaRa - since most basic components (e.g. pipes for the heating grids) are used and extended from here. The medium model in the connector is an extension of the TILMedia class BaseVLEFluid (s. Listing 1). For real fluid behavior this type of medium class is favored. For ideal gas behavior (e.g. assumed for exhaust gas), a Gastypes class from TILMedia is used (not displayed here). An adapter to Modelica.Fluid is provided in ClaRa.

The second type of interface is for the electric systems. The main interface has two variables: active power and frequency (s. Listing 2). Most of the electric models in the coupled energy system models use this interface, since it is sufficient for surveys that do not consider voltage stability, load flow calculations or non-symmetrical 
three phase systems. There are two more electrical interfaces implemented, one adding voltage and reactive power and the the other considering an adjustable number of phases. However, using these advanced electric interfaces to simulate electromagnetic phenomena with time constants in the range of milliseconds has proven to be unmanageable for coupled energy system simulations because of computational restrictions.

Listing 1. Interface for real fluids.

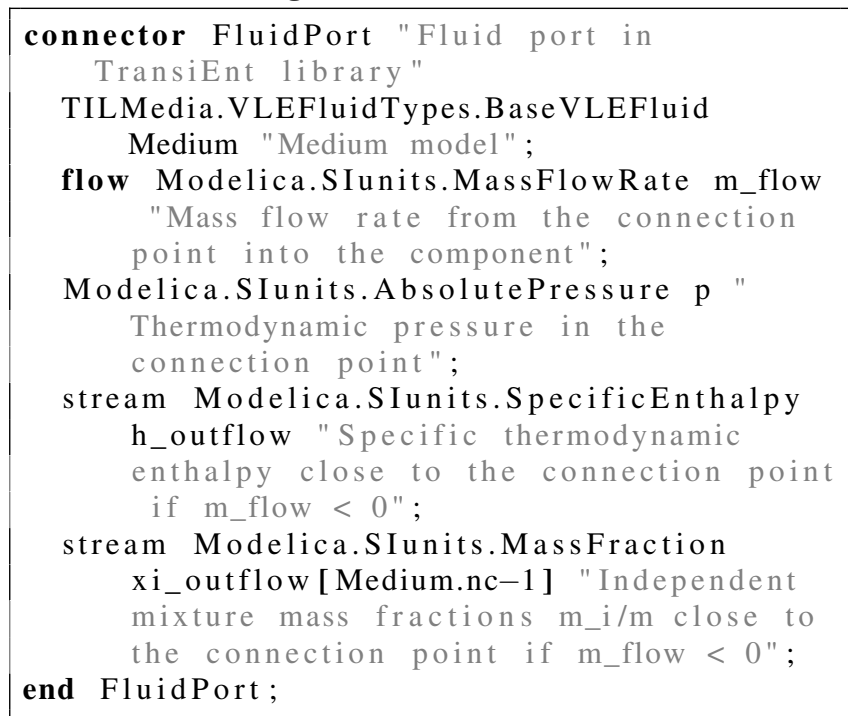

Listing 2. Simple electrical interface.

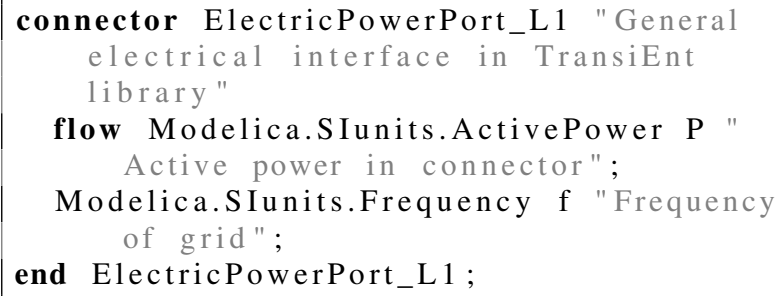

\section{Example of Use: Transient Simula- tion of Coupled Energy Grids}

In this section, an example for a coupled energy grid simulation will be given. Results from the simulated coupled energy system model are presented in order to illustrate the application possibilities of the library.

\subsection{Description}

The Dymola diagram of the system is shown in Figure 4. For consumer and renewable energy power plants static table-based models are used. The models of the electric power and storage plants are also table-based but consider transient effects. The model approach of the largescale CHP plants is described in Section 3.4. The model of the power-to-heat system is first order-based with an equation-based heat exchanger.

As an application example an assumed energy system of Hamburg in the year 2050 is simulated. In this context, energy system means electricity grid and district heating network (DHN). The general assumptions for this future scenario are:

- The electric and district heating demand profiles are the same as in 2012.

- The additional capacities of RE generators in 2050 are based on the expansion scenrios of the Renewable Energy Law (EEG) (Federal Republic of Germany, 2014).

- The structure of the conventional generation park is based on the 2012 generation park in Germany but without nuclear power which is removed without replacement.

- The generation park is scaled down using the peak load of Germany (82 GW) and Hamburg (2 GW), respectively.

- Wind and PV generation profiles (normalized by installed capacity) is the same as in 2012 and taken from 50Herz Transmission GmbH (2015).

- The district heating grid is fed by two black coal CHP plants (CHP Wedel in the west and CHP Tiefstack in the east of the city) and one natural gas peak load heating plant (Heating Plant Hafen in the center of the city).

- The distribution of electric power is not constrained by physical bottlenecks of the transmission or distribution networks.

Prior to the simulation in Dymola the unit commitment schedule of the conventional power park is generated. For this purpose a mixed-integer linear programming model has been derived that is explained in detail in Dubucq and Ackermann (2015) and is solved using the Matlab Optimization Toolbox (The MathWorks Inc., 2014). In essence, this approach allows to minimize the total operational cost of a given electric generation park subject to a list of physical and economic constraints. These are:

- The thermal and electricity demand has to be covered at every instant.

- All power plants are restricted by a minimum and maximum power level and a maximum power generation gradient.

- The pumped storage plant is additionally constrained by energy storage capacity. 


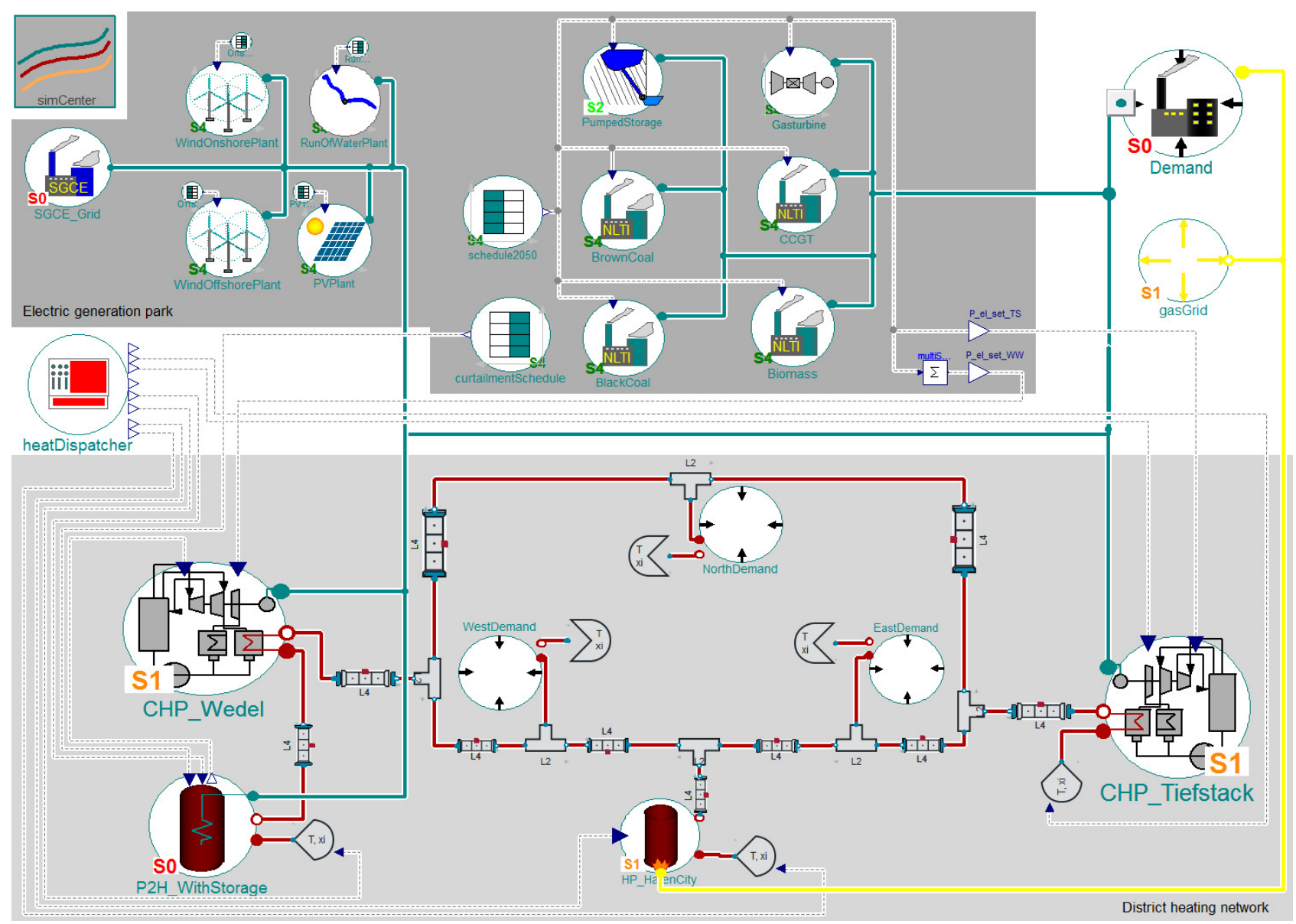

Figure 4. Dymola diagram of the simulated example for the coupled energy grids of Hamburg, showing the electricity generation park (top) and district heating network including the Power-to-Heat units (bottom).

- Minimum and maximum electric generation of CHP plants is depending on the current thermal heat generation.

- RE generation has feed-in priority.

- In every time step a symmetric electric reserve capacity of $\pm 142 \mathrm{MW}$ has to be available to ensure grid stability.

\subsection{Results}

The resulting quarter hourly electricity production schedule is used in the coupled Modelica model (see Figure 4) where the simulation is carried out over an entire year with a variable step solver and the time resolution of the input table data is quarter hourly. All parameters for the considered generation park in this scenario can be found in Table 1.

Figure 5 shows the resulting weekly generated energy by renewable and must-run plants together with the weekly energy demand in 2050. The resulting share of renewable energies in the simulated year is $64 \%$ whereas the targeted value by the German Renewable Energy Law for 2050 is $80 \%$. The reason for this small share in relation to the targeted value is a large amount of RE generation that can not be integrated into the electric grid due to its fluctuating nature on the one hand and non-dispatchable generation units on the other hand. The non-dispatchable generation consists of three components: the first component is the above mentioned electric reserve capacity of $\pm 142 \mathrm{MW}$ that must be available in order to compensate power imbalances and thus ensuring electric grid stability. Secondly, every CHP plant has a specific minimum electric power generation depending on the current thermal heat generation needed to match the district heating demand. The third component is the RE generation that has priority feed-in by the EEG (Federal Republic of Germany, 2014). However, as can be seen from Figure 5, the renewable generation cannot fully be used, due to the first two components of nondispatchable generation and a lack of storage capacities. This leads to the operational necessity to curtail renewable energy generation in 3831 hours of the year which amounts to $2.39 \mathrm{TWh}$. Even though the yearly generated energy from non-dispatchable sources (13.3 TWh) is only $3 \%$ higher than the electric energy consumption $(12.9 \mathrm{TWh})$, a fossil generation of $4.66 \mathrm{TWh}$ is needed to match the electric demand at all times. 
Table 1. Parameters of the simulated electricity generation park.

\begin{tabular}{|c|c|c|c|c|c|c|c|}
\hline Plant Type & Capacity & Efficiency & $\begin{array}{l}\mathrm{CO}_{2} \text {-Emissions } \\
\text { Power }\end{array}$ & $\begin{array}{l}\text { Minimum } \\
\text { Gradient }\end{array}$ & Maximum Power & Var. Costs & Start-up Costs \\
\hline & MW & $\%$ & & & $\% / \min$ & €/MWh & €/MW \\
\hline Brown Coal & 574 & 34 & 403 & 40 & 6 & 22.7 & 81.8 \\
\hline Black Coal & 688 & 40 & 337 & 30 & 8 & 27.9 & 81.8 \\
\hline CCGT & 598 & 52 & 202 & 20 & 10 & 48.2 & 30.5 \\
\hline Gas Turbines & 133 & 35 & 202 & 20 & 12 & 100.2 & 16.5 \\
\hline Pumped Storage & 173 & & 0 & 0 & 100 & 35.3 & 0 \\
\hline Biomass & 322 & & 0 & 0 & 100 & 38.3 & 0 \\
\hline Run-Off Water & 123 & & & & & & \\
\hline Photovoltaic & 2446 & & & & & & \\
\hline Wind Onshore & 2753 & & & & & & \\
\hline Wind Offshore & 1327 & & & & & & \\
\hline Sum & 9137 & & & & & & \\
\hline
\end{tabular}

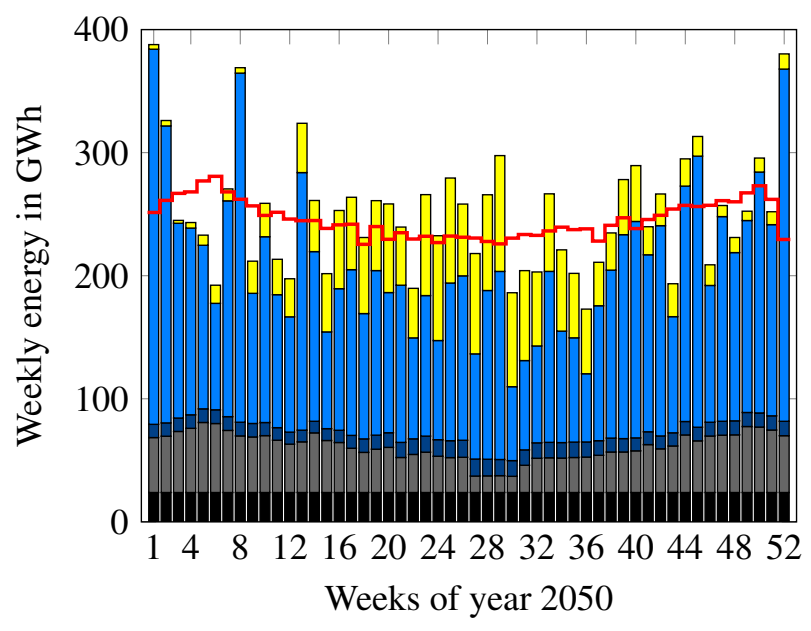

Figure 5. Weekly averaged energy consumption (-), and must-run generation: Spinning reserve ( $)$, Minimum generation from CHP plants ( $\square$ ), Run-Off Water $(\square)$, Wind $(\square)$ and Photovoltaic ( $\longrightarrow$ ) plants.

These results demonstrate the need for storage capacities and flexibility options to reach higher shares of RE generation. The objective of the developed library is to investigate measures resulting from a coupled system simulation approach that takes into account not only the electric but also the heat demand. One option following from this approach is to use the excess electricity to cover the heat demand (Power-to-Heat) and thereby using the district heating grid as a flexibility option. In fact, it has been proposed to install up to four $25 \mathrm{MW}$ electric steam generators in the district heating grid of Hamburg together with a $1.9 \mathrm{GWh}$ hot water storage in order to increase the flexibility of heat production in the western CHP plant (Erker, 2013). In order to assess the impact of such a measure another yearly simulation has been carried out in which such electric steam generators and a hot water storage have been added to the model. The results for electric and thermal power generation from this simulation together with the results from the base scenario can be found in Figure 6 for the first week of 2050 in quarter hourly resolution. As can be seen from the illustrated week very large amounts (up to $2 \mathrm{GW}$ ) of excess generation occur in the year 2050 which can not be used in the electric grid due to lack of storage capacities. The $173 \mathrm{MW}$ pumped storage plant can only shift $162 \mathrm{GWh}$ of otherwise curtailed electric generation to periods of low renewable generation, whereas the total surplus energy amounts to $2.39 \mathrm{TWh}$ during the entire year. While the renewable generation covers most of the demand, the must-run generation from the two CHP plants that cover the district heating grid demand is always present during the illustrated winter week. Despite the large excess generation from RE generators their non-dispatchable nature becomes clear visible in some periods (e.g. Monday morning and Friday noon), where dispatchable plants have to start up to cover demand in order to compensate for the decreasing wind energy offer.

The increased flexibility of the energy system introduced by the Power-to-Heat units leads to a use of $362.4 \mathrm{GWh}$ of otherwise curtailed renewable energy $(15.2 \%)$ as can be seen in the bottom, right part of Figure 6. While the Power-to-Heat unit has only minor impact on the electric dispatch it does replace thermal generation from the black coal CHP plant by virtually emission free generation from RE sources. This effect can further be examined in Figure 7 where the mass of $\mathrm{CO}_{2}$ emissions in both future scenarios and a 2012 base scenario are illustrated for the entire year. Comparing the results for the 2012 scenario and the future scenarios the effect of RE integration on $\mathrm{CO}_{2}$ emissions becomes obvious with a total reduction of 5.9 million tons of $\mathrm{CO}_{2}$ emissions from electricity generation which is equivalent to a $70.8 \%$ reduction of emissions in the simulated energy system. This is also equivalent to a $80 \%$ reduction with respect to emission from electricity in 1990 which is equal to the value stated by the German government coalition agreement (Federal Republic of Germany, 2013). However, it should be noted that this targeted value applies to the total $\mathrm{CO}_{2}$ emissions in germany (including emissions from transportation, etc.). The spe- 

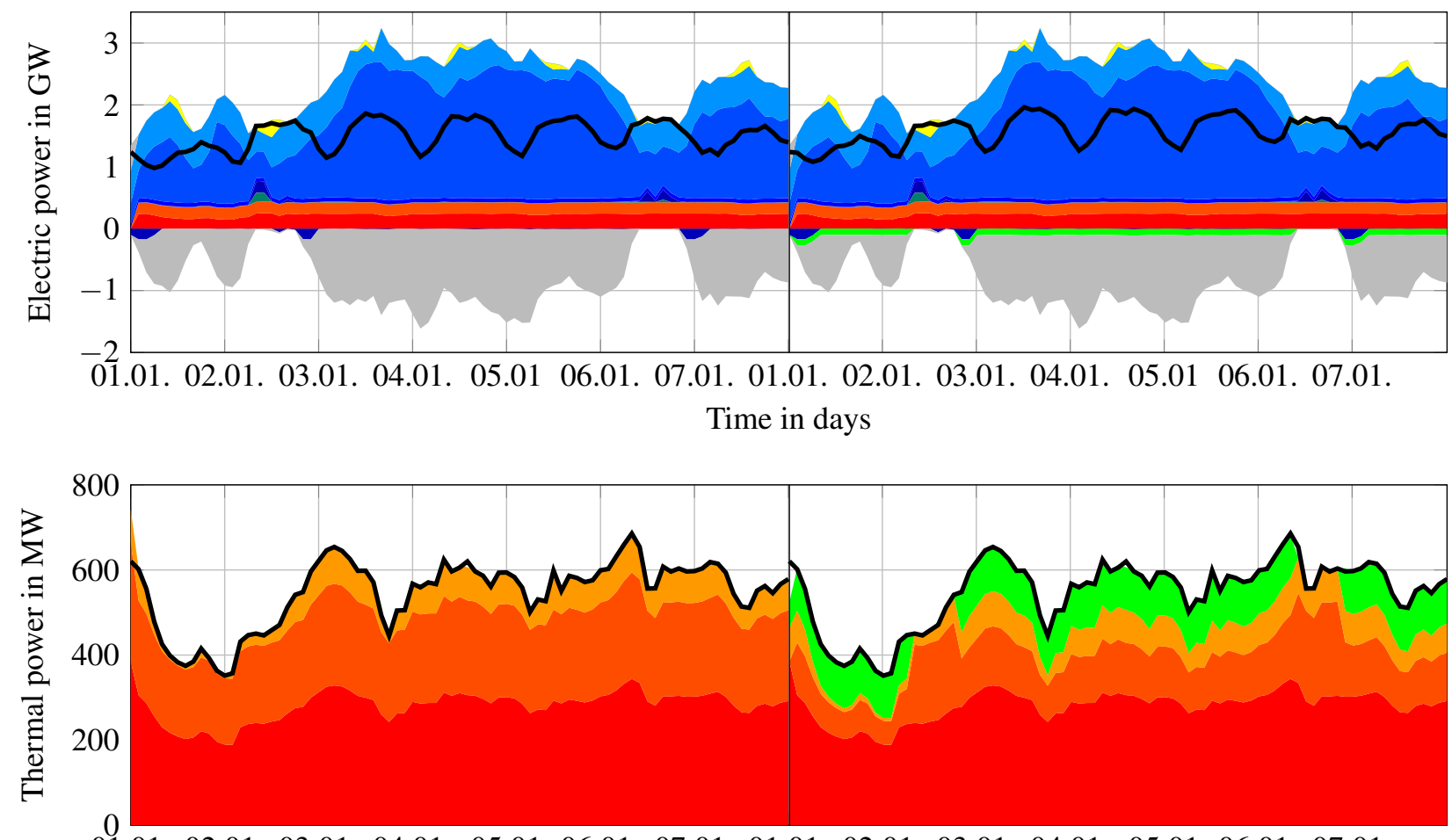

01.01. 02.01. 03.01.04.01.05.01 06.01. 07.01. 01.01. 02.01. 03.01. 04.01. 05.01 06.01. 07.01.

Time in days

Figure 6. Simulated electric (top) and thermal (bottom) power generation in Hamburg for the first week (Sunday till Saturday) of 2050 scenario without Power-to-Heat (left) and with Power-to-Heat (right).

Biomass Pumped Storage Run-Off Water Excess Electricity Generation Heating Plant Hafen Demand (bottom).

cific emission from electricity generation of the 2012 reference simulation amounts to $587 \mathrm{~g} / \mathrm{kWh}$ whereas statistical evaluations in (Umweltbundesamt, 2015) give a slightly lower value of $562 \mathrm{~g} / \mathrm{kWh}$. This deviation is due to the replacement of nuclear plants that are emissionfree.

The additionally used RE generation in the Power-toHeat future scenario leads to a reduction of 51.2 thousand tons of $\mathrm{CO}_{2}$ emissions. This is equivalent to a $8.3 \%$ reduction of emissions from district heating grid operation and $1.7 \%$ of total emissions in the simulated coupled system (electricity grid and DHN) with respect to the future scenario without Power-to-Heat. The specific emissions of district heating generation are reduced from $143 \mathrm{~g} / \mathrm{kWh}$ to $131 \mathrm{~g} / \mathrm{kWh}$. The States of Germany working group of energy balances quantifies the specific DHN emissions of Hamburg in 2012 to $203 \mathrm{~g} / \mathrm{kWh}$ (LAKEnergiebilanzen, 2015). One reason for this deviation is that the total production, hence total $\mathrm{CO}_{2}$ mass flow emission, of the CHP plants is lower due to the increased $\mathrm{RE}$ electric generation. Another possible explanation is the method used for the allocation of $\mathrm{CO}_{2}$ emissions to heat and electricity production from CHP plants. In the presented results the allocation is done using the simpli- fied efficiency method described in (Mauch et al., 2010):

$$
\begin{gathered}
\dot{m}_{\mathrm{CO}_{2}, \text { el }}=\dot{m}_{\mathrm{CO}_{2}, \text { tot }} \cdot \frac{\eta_{\mathrm{th}}}{\eta_{\mathrm{th}}+\eta_{\mathrm{el}}} \\
\dot{m}_{\mathrm{CO}_{2}, \text { th }}=\dot{m}_{\mathrm{CO}_{2}, \text { tot }} \cdot \frac{\eta_{\mathrm{el}}}{\eta_{\mathrm{th}}+\eta_{\mathrm{el}}}
\end{gathered}
$$

where $\dot{m}_{\mathrm{CO}_{2} \text {,tot }}$ denotes the total $\mathrm{CO}_{2}$ emissions and $\eta_{\text {th }}$ and $\eta_{\mathrm{el}}$ are the thermal and electric efficiency of the CHP plant respectively. This method however, allocates a larger amount of emissions to the electrical side since the electrical efficiency is smaller than the thermal heat production efficiency which takes into consideration the fact that electricity is pure exergy and in this sense thermodynamically more valueable. The allocation method used in (LAK-Energiebilanzen, 2015) is the alternative generation method which leads to somewhat higher emissions on the thermal side (Mauch et al., 2010). In the final library different methods for $\mathrm{CO}_{2}$ allocation will be made available to the user using replaceable models.

The time evolution of the $\mathrm{CO}_{2}$ emissions from DHN operation is dependent on the season which is noticeable by the slope of the curve that is high during heating periods and low during the summer. This also applies to emissions from electricity generation because a decrease 


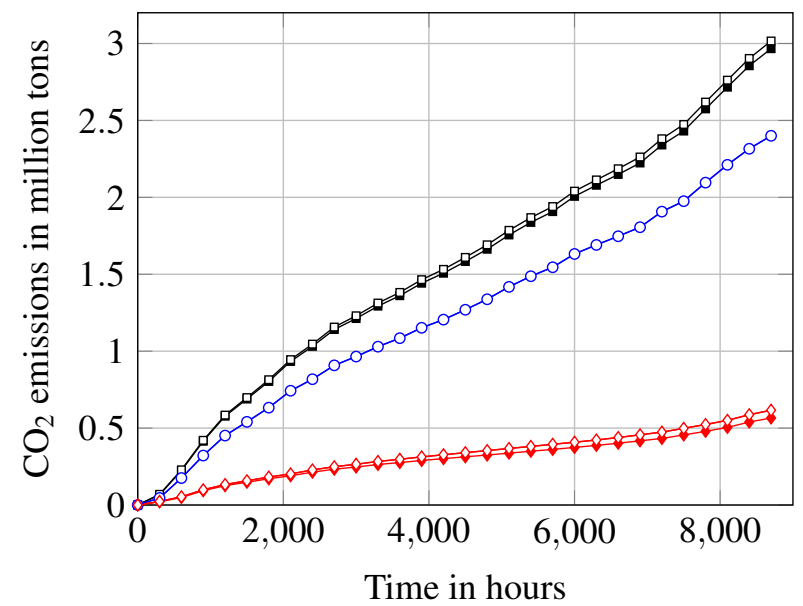

Figure 7. $\mathrm{CO}_{2}$ emissions in future base scenario (empty symbols) and future scenario with Power-to-Heat units (filled symbols). Total emissions of electricity generation and DHN operation $(\square)$, emissions from electricity generation $(-)$ and emissions from DHN thermal generation $(\diamond)$.

in heat demand also leads to a decrease of must-run capacity (see also Figure 5).

\section{Summary and Outlook}

In this paper the development status of the TransiEnt library is presented. The library is being developed within the TransiEnt.EE research project. After project completion, the library will be made freely available under the terms of the Modelica license agreement. Although the library is still in the development phase, its current status already allows the simulation of RE integration scenarios.

In particular, the exemplary simulation showed that the curtailment of RE could be effectively reduced by the use of power-to-heat and heat storage units. Under the selected assumptions, $15.2 \%$ of the originally curtailed energy could be integrated. This additional flexibility measure also leads to a reduction of the system's $\mathrm{CO}_{2}$ emissions. Under the selected assumptions, the $\mathrm{CO}_{2}$ emissions of the electricity generation and district heating operation together are reduced by $1.7 \%$. The $\mathrm{CO}_{2}$ emissions of the district heating network operation are reduced by $8.3 \%$.

In the following project phase, the development team will focus on the detailed definition of the project scenarios, which include a central-oriented scenario, a decentralized scenario, a demand-side-management scenario and a storage scenario. In the mean time, the development of the library will continue. This development pursues the modeling of additional components and the improvement of existing ones, considering the requirements evolving from the scenarios.

\section{Acknowledgements}

The authors would like to acknowledge all supporters of the TransiEnt.EE research project, especially XRG Simulation $\mathrm{GmbH}$ and the project's advisory board. The project is funded by the German Federal Ministry for Economic Affairs and Energy on the basis of a decision by the German Bundestag (BMWi 03ET4003).

\section{References}

50Herz Transmission GmbH. Grid Data, 2015. URL http: //www.50hertz.com/en/Grid-Data.

BMWi. Ein Strommarkt für die Energiewende - Diskussionspaper des Bundesministeriums für Wirtschaft und Energie (Grünbuch). Technical report, Bundesministerium für Wirtschaft und Energie, 2014.

Johannes Brunnemann, Friedrich Gottelt, Kai Wellner, Ala Renz, Andre Thüring, Volker Roeder, Christoph Hasenbein, Christian Schulze, Gerhard Schmitz, and Jörg Eiden. Status of claraccs: Modelling and simulation of coal-fired power plants with $\mathrm{co}_{2}$ capture. In Proceedings of the $9^{\text {th }}$ International Modelica Conference, September 2012.

Ernst Chudzienski. Hamburgs größte Wärmetransportleitung im Bau. Fernwärme International, 5(16):328-338, 1987.

ClaRa Library, 2015. URL http://www.claralib. $\mathrm{com} /$.

Dassault Systemes. Dymola, 2012. URL http: //www.3ds.com/products-services/catia/ products/dymola.

Pascal Dubucq and Günter Ackermann. Frequency Control in Coupled Energy Systems with High Penetration of Renewable Energies. In International Conference on Clean Electric Power, pages 336-342, Taormina, 2015. IEEE.

ENTSO-E. European Network of Transmission System Operators for Electricity, 2015. URL http: / / www . ent soe. eu.

Martin Erker. Innovationskraftwerk Wedel, 2013.

European Commission. A Roadmap for moving to a competitive low carbon economy in 2050. Technical report, European Commission, 2011.

Federal Republic of Germany. Coalition agreement 18th legislative period, 2013. URL http://www.bundesregierung.de/ Content/DE/StatischeSeiten/Breg/ koalitionsvertrag-inhaltsverzeichnis. html.

Federal Republic of Germany. Gesetz für den Ausbau erneuerbarer Energien (Erneuerbare-EnergienGesetz - EEG 2014), 2014. URL http: //www.bmwi.de/BMWi/Redaktion/PDF/G/ gesetz-fuer-den-ausbau-erneuerbarer $\backslash$ -energien, property=pdf, bereich= bmwi2012, sprache=de, rwb=true.pdf. 
Hamburg University of Technology. TransiEnt.EE Project, 2013-2016. URL http://www.tu-harburg.de/ transient-ee.

Alfons Kather, Volker Röder, Christoph Hasenbein, Gerhard Schmitz, Kai Wellner, Friedrich Gottelt, and Lasse Nielsen. DYNCAP - Dynamische Untersuchung von Dampfkraftprozessen mit $\mathrm{CO}_{2}$-Abtrennung zur Bereitstellung von Regelenergie. Final report, Bundesministerium für Wirtschaft und Energie, 2014.

LAK-Energiebilanzen. Spezifische CO2-Emissionen der Strom- und Fernwärmeerzeugung in $\mathrm{kg}$ CO2/GJ (Stand 20.07.2015), 2015. URL http: //www.lak-energiebilanzen.de/dseiten/ co2BilanzenAktuelleErgebnisse.cfm.

Wolfgang Mauch, Roger Corradini, Karin Wiesemeyer, and Marco Schwentzek. Allokationsmethoden für spezifische $\mathrm{CO}_{2}$ - Emissionen von Strom und Wärme aus KWKAnlagen. Energiewirtschaftliche Tagesfragen, 55(9):2-4, 2010.

The MathWorks Inc. Optimization Toolbox, 2014. URL http://de.mathworks.com/products / optimization/.

TLK Thermo GmbH. TILMedia Suite, 2015. URL http://www.tlk-thermo.com/en/ software-products/tilmedia.html.

Umweltbundesamt. Entwicklung des $\mathrm{CO}_{2}$-Emissionsfaktors für den Strommix in Deutschland in den Jahren 1990 bis 2012 (in Gramm pro Kilowattstunde), 2015. URL http://de.statista.com/ statistik/daten/studie/38897/umfrage/ co2-emissionsfaktor-fuer-den-strommix -in-deutschland-seit-1990. 